\title{
The Sheffield omission training procedure applied to the conditioning of the licking response in rats
}

RICHARD L. PATTEN, IOWA STATE UNIVERSITY JERRY W, RUDY ${ }^{\prime}$, UNIVERSITY OF RICHMOND
A classical conditioning situation was modified to make the US contingent on the nonoccurrence of the CR (anticipatory licking by rats). Ss did not leam the rewarded response. Classical conditioning of anticipatory licking developed in spite of a rapidly decreasing frequency of US presentations over conditioning sessions.

F. D. Sheffield (1965) coined the term "omission training" to refer to a modified classical conditioning procedure in which the unconditioned stimulus (US) is withheld if an anticipatory conditioned response (ACR) occurs, and is presented if the ACR does not occur. Sheffield designed the omission training technique as a test of the "reinforcement" (law-of-effect) interpretation of classical salivary conditioning in dogs. Although the general trend of his results fell against the reinforcement theory, Sheffield ran into difficulties with the long latency of the conditioned salivary response, and was not able to collect an adequate amount of clearly interpretable data.

A number of recent studies (Miller, 1961; Patten \& Deaux, 1966; Patten \& Rudy, 1967) have reported classical conditioning of the licking response in rats. The licking ACR in rats is a very short latency response, and so was regarded as more suitable than salivation for employment in the omission training procedure. The present study employed the omission training procedure to investigate the possibility that "reinforcement" (i.e., ACR-US contingency) controls the development of the ACR in rats.

\section{Method}

The Ss were 12 naive female Wistar albino rats, 125-135 days old at the start of habituation to handling and deprivation, six of which were randomly assigned to each of two experimental groups.

The apparatus was essentially the same as used in a previous study (Patten \& Rudy, 1967) with the major exception that a compound CS (light plus tone) was used in the present study. Briefly, the response recording technique consisted of S's wearing a leather and stretch-nylon headgear which held an aluminum US delivery tube in place approximately $1 / 8 \mathrm{in}$. in front of S's mouth. A Hunter contact relay in series with an electric circuit through $S$ detected each contact S's tongue made with the US tube.

During conditioning sessions $S$ was maintained on a 31 in. $x 35$ in. elevated platform. The only restraint on S's movement came from two contact wires and vinyl tubing through which the US reached the drinking tube. The wires and vinyl tubing were loosely suspended from above $S$ to permit freedom of locomotor movement and to prevent S's becoming entangled in the wires.

Licking was recorded for all Ss during a $3 \mathrm{sec}$ period preceding CS-onset and, separately, during the first $3 \mathrm{sec}$ of the CS, which consisted of a $550 \mathrm{cps}, 35 \mathrm{~dB}$ tone and the light (.34 ft-c at $10 \mathrm{in.}$ ) from a darkened $15 \mathrm{~W}$ bulb. The CS bulb was centered on the edge of a long side of the platform. The US $(.40 \mathrm{ml}$ of a $15 \%$ sucrose solution) was delivered during the fourth second after CS-onset. For one group of six Ss (Group A), the CS terminated with US-offset; for the second group of six Ss (Group B), the CS terminated with US-onset.

All Ss were habituated to a $23 \mathrm{~h}$ water deprivation schedule beginning seven days before experimental training, and were deprived of water for $23 \mathrm{~h}$ prior to each daily experimental session. Ss were also handled and habituated to the headgear for approximately 5 min on each of the seven pretraining days.

Ss received 25 presentations of the CS during each of the 11 daily sessions of acquisition training. $S$ received a CS-US pairing on trials in which he did not lick the US tube during the $3 \mathrm{sec} C S-U S$ interval. CS presentations occurred at randomized intertrial intervals (ITIs) of 45,50 , and $55 \mathrm{sec}$, with a mean of $50 \mathrm{sec}$. The ITI schedule was modified to exclude a continuous sequence of three or more identical ITIs.

\section{Results and Discussion}

Figure 1 presents the not-licking performance over blocks of daily conditioning sessions for both experimental groups combined (the performance curves for Groups A and B were virtually identical). It can be seen that not-licking performance steadily deteriorates over the 11 conditioning sessions. A significant Sessions effect $(F=8.56, d f=10 / 100, p<.01)$ supports the observed performance decline. Ss received, on the average, only three out of a possible 25 "reinforcements" during the Days 10-11 block of trials.

For each trial the number of licks in the $3 \mathrm{sec}$ pre-CS scoring interval was subtracted from the number of licks in the 3 sec CS-US scoring interval to provide a score of discriminated licking to the CS. Figure 2 presents the means of the individual difference licking scores calculated over the daily session blocks of trials indicated on the abscissa. A significant Sessions effect $(F=8.56, d f=10 / 100, p<.01)$ 


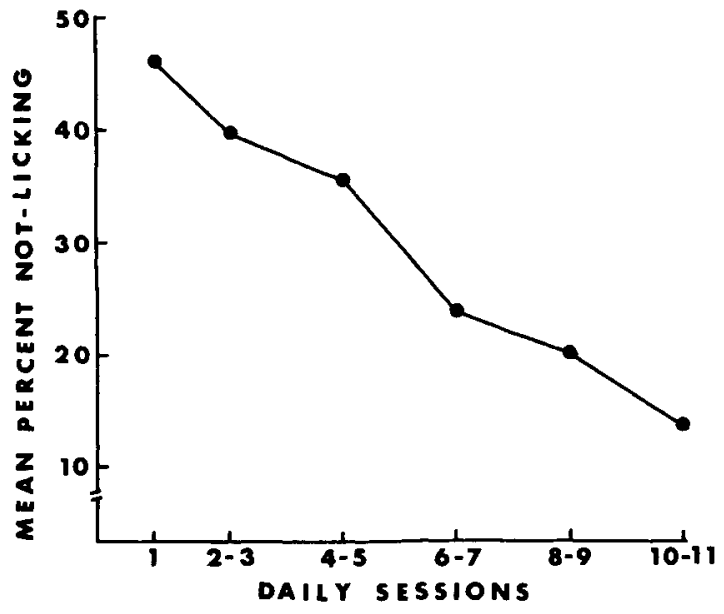

Fig. 1. Not-licking performance over blocks of daily conditioning sessions.

supports the conclusion that, despite the decreasing frequency of CS-US pairings, classically conditioned licking did develop.

Figure 3 presents the session means of the individual licking scores during the 3 sec pre-CS and CS-US scoring intervals. A significant Sessions effect

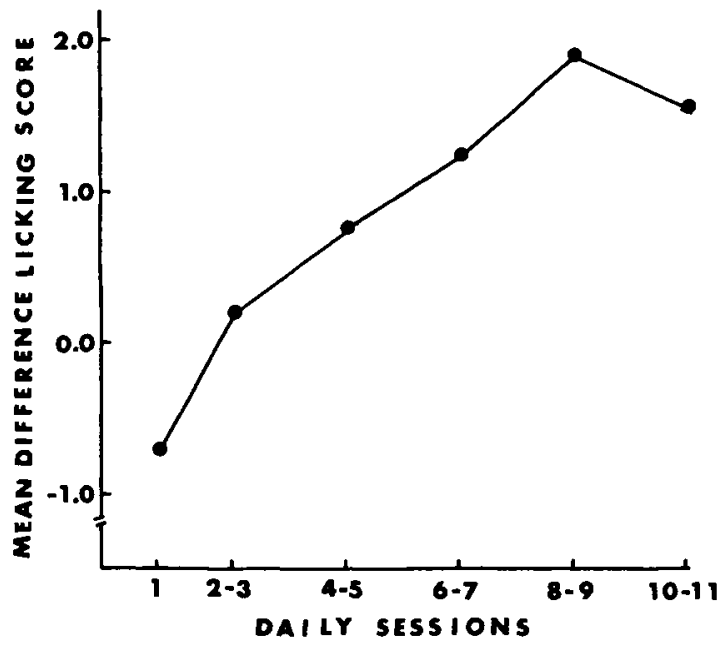

Fig. 2. Means of individual difference licking scores over blocks of daily acquisition sessions.

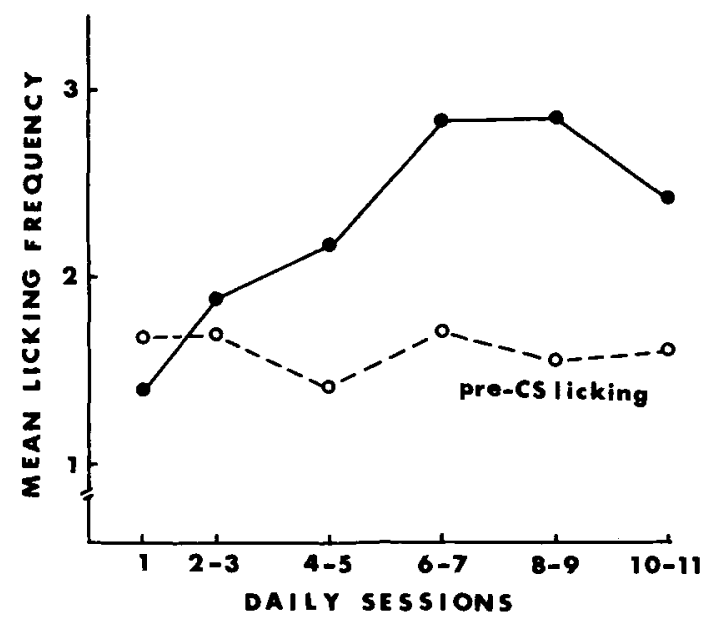

Fig. 3. Means of individual licking scores during pre-CS and CS-US scoring intervals.

$(F=5.18, \mathrm{df}=10 / 100, \mathrm{p}<.01)$ was associated with licking during the CS-US scoring interval. A corresponding analysis of pre-CS licking $(F=1.38, \mathrm{df}=10 / 100, \mathrm{p}>.05)$ indicated that Sessions was not a significant source of pre-CS variance. Thus, the increase over sessions in mean difference licking scores indicated in Fig. 2 was due to the development of licking to the CS.

The data obtained in the present study quite clearly indicate that: (1) Not licking did not come under the control of the response-"reinforcement" contingency utilized in the present study. (2) Anticipatory licking to the CS did develop in spite of the absence of ACR"reinforcement" pairings.

\section{References}

Miller, N. Analytical studies of drive and reward. Amer. Psychologist, 196 1, 16, 739-754.

Patten, R. L., \& Deaux, E. B. Classical conditioning and extinction of the licking response in rats. Psychon. Sci., 1966, 4, 21-22.

Patten, R. L., \& Rudy, J. W. Orienting during classical conditioning: Acquired versus unconditioned responding. Psychon. Sci., 1967, 7, 27-28.

Sheffield, F. D. Relation between classical conditioning and instrumental learning. In W. F. Prokasy (Ed.), Classical conditioning: A symposium. New York: Appleton-Century-Crofts, 1965. Pp. 302-322.

\section{Note}

1. Now at the University of Virginia. 